\title{
Effects of Radiation Exposure on the Cost-Effectiveness of CT Angiography and Perfusion Imaging in Aneurysmal Subarachnoid Hemorrhage
}

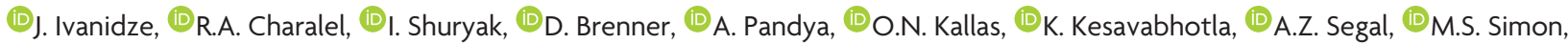 \\ and $(1$ P.C. Sanelli
}

\begin{abstract}
BACKGROUND AND PURPOSE: CT angiography and perfusion imaging is an important prognostic tool in the management of patients with aneurysmal subarachnoid hemorrhage. The purpose of this study was to perform a cost-effectiveness analysis of advanced imaging in patients with $\mathrm{SAH}$, incorporating the risks of radiation exposure from CT angiography and CT perfusion imaging.
\end{abstract}

MATERIALS AND METHODS: The risks of radiation-induced brain cancer and cataracts were incorporated into our established decision model comparing the cost-effectiveness of CT angiography and CT perfusion imaging and transcranial Doppler sonography in SAH. Cancer risk was calculated by using National Cancer Institute methodology. The remaining input probabilities were based on literature data and a cohort at our institution. Outcomes were expected quality-adjusted life years gained, costs, and incremental cost-effectiveness ratios. One-way, 2-way, and probabilistic sensitivity analyses were performed.

RESULTS: CT angiography and CT perfusion imaging were the dominant strategies, resulting in both better health outcomes and lower costs, even when incorporating brain cancer and cataract risks. Our results remained robust in 2-way sensitivity analyses varying the prolonged latency period up to 30 years, with either brain cancer risk up to 50 times higher than the upper $95 \% \mathrm{Cl}$ limit or the probability of cataracts from 0 to 1. Results were consistent for scenarios that considered either symptomatic or asymptomatic patients with SAH. Probabilistic sensitivity analysis confirmed our findings over a broad range of selected input parameters.

CONCLUSIONS: While risks of radiation exposure represent an important consideration, CT angiography and CT perfusion imaging remained the preferred imaging compared with transcranial Doppler sonography in both asymptomatic and symptomatic patients with $\mathrm{SAH}$, with improved health outcomes and lower health care costs, even when modeling a significantly higher risk and shorter latency period for both cataract and brain cancer than that currently known.

ABBREVIATIONS: $\mathrm{CTAP}=\mathrm{CT}$ angiography and $\mathrm{CT}$ perfusion; $\mathrm{NCI}=$ National Cancer Institute; $\mathrm{QALY}=$ quality-adjusted life year; $\mathrm{TCD}=$ transcranial $\mathrm{Doppler}$ sonography

A neurysmal subarachnoid hemorrhage is a devastating illness with the reported incidence estimated as 14.5 per 100,000 person years in the United States. ${ }^{1} \mathrm{SAH}$ is associated with a mortality of $15 \%$, and approximately $58 \%$ of survivors experience functional disability, with global cognitive impairment being a major contributor to poor functional status. ${ }^{2} \mathrm{SAH}$ is also associ-

Received August 16, 2016; accepted after revision October 3.

From the Departments of Radiology (J.I., R.A.C., O.N.K., K.K., P.C.S.), Neurology (A.Z.S.), and Internal Medicine and Public Health (M.S.S.), Weill Cornell Medical College, NewYork-Presbyterian Hospital, New York, New York; Department of Radiology (I.S., D.B.), NewYork-Presbyterian Hospital, Columbia University Medical Center, New York, New York; Department of Health Policy and Management (A.P.), Harvard T.H. Chan School of Public Health, Boston, Massachusetts; and Department of Radiology (M.S.S., P.C.S.), Northwell Health, Manhasset, New York.

This work was supported by the Radiological Society of North America Research and Education Foundation (Resident Research Grant RR1429 to Jana Ivanidze).

Preliminary results of this work were presented as an oral scientific paper presentation at: Annual Meeting of the Radiological Society of North America, November 30 to December 5, 2014; Chicago, Illinois. ated with a considerable economic burden, with average inpatient costs of $\$ 150,101$ for patients with symptomatic vasospasm in the United States and \$110,310 for patients without symptomatic vasospasm. ${ }^{3}$ A study conducted in the United Kingdom in 2010 found the total annual economic burden of SAH to be approxi-

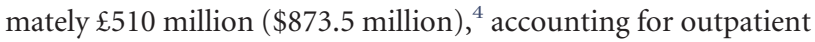
care, cerebrovascular rehabilitation, and social services. The same study found an estimated annual total of 74,807 quality-adjusted life years (QALYs) lost due to SAH. Therefore, SAH is associated with a substantial burden on health care resources, most of which are related to the long-term effects of functional and cognitive disability.

The marked increase in CT use during the past several decades

Please address correspondence to Jana Ivanidze, MD, PhD, Department of Radiology, NewYork-Presbyterian Hospital/Weill Cornell Medicine, New York, NY 10065; e-mail: jai9018@nyp.org; @jana_ivanidze

http://dx.doi.org/10.3174/ajnr.A5034 
Table 1: Input parameters added into the decision analytic model incorporating the effects of radiation exposure

\begin{tabular}{lcl}
\hline \multicolumn{1}{c}{ Input Parameter } & Value & \multicolumn{1}{c}{ Source } \\
\hline Probability of brain cancer & $\begin{array}{c}27.35 \text { per 100,000 } \\
\text { person years }\end{array}$ & $\begin{array}{l}\text { Calculated using NCI methodology } \\
\text { (Berrington de Gonzalez et al, }\end{array}$ \\
& & $\begin{array}{l}15 \\
\text { main text for further details) }\end{array}$ \\
Probability of cataract & 0.0025 & $\begin{array}{l}\text { Yuan et al } \\
\text { Kranzinger et al }^{12}\end{array}$ \\
Latency of brain cancer & $10.7 \mathrm{yr}$ & Henk et al $^{14}$ \\
Latency of cataract & $6 \mathrm{yr}$ & de Rooij et al $^{19}$ \\
Utility of brain cancer & 0.69 & Kallmes and Kallmes $^{20}$ \\
Utility of cataract & 0.86 & de Rooij et al \\
Cost of brain cancer & $\$ 49,301.70$ & Kallmes and Kallmes \\
Cost of cataract & $\$ 2692$ &
\end{tabular}

\section{MATERIALS AND METHODS Model Structure}

Our established decision-analysis model was developed by using the TreeAge Pro software program (Version 2013.1.0; TreeAge Software, Williamstown, Massachusetts). ${ }^{9}$ The model compares the health and economic consequences of 2 imaging strategies for management of SAH: TCD and CTAP. Following aneurysmal rupture, patients with SAH are classified as either symptomatic or asymptomatic for complications such as

Table 2: Lifetime brain cancer risks ${ }^{\mathrm{a}}$

\begin{tabular}{cccc}
\hline $\begin{array}{c}\text { Age at } \\
\text { Treatment } \\
\text { (yr) }\end{array}$ & Sex & $\begin{array}{c}\text { Life } \\
\text { Expectancy } \\
\text { (mRS Score) }\end{array}$ & $\begin{array}{c}\text { Lifetime Brain Cancer Risk } \\
\text { (per 100,000 Individuals) } \\
\text { (Mean) (95\% CI) }\end{array}$ \\
\hline 70 & M & Normal (0-2) & $8.14(1.52-23.82)$ \\
70 & M & Reduced (3-5) & $2.33(0.44-6.82)$ \\
70 & F & Normal (0-2) & $2.47(0.52-6.84)$ \\
70 & F & Reduced (3-5) & $0.66(0.14-1.83)$ \\
50 & M & Normal (0-2) & $27.35(5.25-80.16)^{\mathrm{b}}$ \\
50 & M & Reduced (3-5) & $5.26(1.01-15.40)$ \\
50 & F & Normal (0-2) & $7.32(1.55-20.36)$ \\
50 & F & Reduced (3-5) & $1.39(0.29-3.85)$ \\
\hline
\end{tabular}

a Risks were calculated using $\mathrm{NCl}$ methodology (https://irep.nci.nih.gov/radrat/), adjusted for life expectancy. ${ }^{15}$ The average dose for a CT+CTA + CTP examination was estimated from published literature. ${ }^{16}$

b To assume a conservative approach, we used the highest modeled risk (50-year-old male patient with normal life expectancy) for our base case scenario.

has revolutionized the practice of medicine and is associated with a marked rise in administered radiation doses. ${ }^{5}$ This increase in radiation dose is attributable, in part, to the increased speed of image acquisition, allowing multiphase examinations to evaluate greater coverage of the body and provide functional information. This has resulted in a significant increase in the population's cumulative exposure to ionizing radiation and concern for the potential increase in cancer risk. ${ }^{6}$ In 2009, the US Food and Drug Administration issued a notification regarding the safety of CT perfusion in administering high radiation doses. ${ }^{7}$ Consequently, there has been a focus on reducing radiation exposure from medical imaging and evaluating the appropriate use of $\mathrm{CT}{ }^{8}$

The purpose of our study was to incorporate the short- and long-term risks of ionizing radiation exposure from CT angiography and CT perfusion (CTAP) imaging into our established cost-effectiveness decision model of patients with aneurysmal subarachnoid hemorrhage ${ }^{9}$ to determine whether the risks of radiation-induced brain cancer and cataracts would potentially alter the model results. In our previous work, which did not include the downstream effects of radiation exposure from CTAP on health outcomes and health care costs, our model results indicated that CTAP is the preferred imaging strategy compared with transcranial Doppler sonography (TCD), leading to improved clinical outcomes and lower health care costs in patients with SAH. ${ }^{9}$ Our hypothesis is that CTAP will remain the preferred imaging strategy in patients with SAH due to its relatively low risk from radiation exposure coupled with the high morbidity and mortality rates in this patient population. vasospasm and/or delayed cerebral ischemia. The test result of either TCD or CTAP leads to management options, including no treatment (patient observation), immediate treatment with medical hypertensive therapy, and further testing by using digital subtraction angiography with potential interventional treatment. The organization of the branches in the model is based on the Guidelines for the Management of Aneurysmal Subarachnoid Hemorrhage published by the American Heart Association/ American Stroke Association ${ }^{10}$ and a clinical decision-making algorithm derived from consultation with 4 neurologists specializing in neurointensive care at New York-Presbyterian Hospital Weill Cornell Campus for specific clinical scenarios.

\section{Patient Population}

The base case scenario is a 50-year-old patient, representing the average age in a previously described $\mathrm{SAH}$ cohort at our institution. ${ }^{9}$ Inclusion criteria for the empiric patient cohort are described in detail in our previously published decision analytic model. ${ }^{9}$ Briefly, this cohort included adult patients with documented aneurysmal SAH at admission enrolled in an internal review board-approved prospective diagnostic accuracy trial at our institution. Patients underwent aneurysm repair and were monitored in the neurologic intensive care unit, as per the standard of care. Patients were defined as symptomatic if they had documented clinical deterioration with the occurrence of focal neurologic impairment or a decrease of at least 2 points on the Glasgow Coma Scale that was new and not attributable to other causes. Patients who did not experience the above symptoms were defined as asymptomatic. All patients were imaged with CTAP on the day of occurrence of symptoms or on days 6-8 in case of asymptomatic patients. Patients who had negative CTAP findings were managed conservatively. Patients who had positive CTAP findings received medically induced hypertensive therapy as per standard guidelines. ${ }^{11}$ Patients who did not respond to medical therapy proceeded to angiographic testing. If angiographic testing was positive for vasospasm, patients were treated intraprocedurally with intra-arterial verapamil.

\section{Input Probabilities}

Input Parameters Derived from Published Literature. Table 1 lists all input parameters incorporated in our expanded decision analytic model incorporating the effects of radiation exposure. All other preexisting input parameters are described in detail in our previously published decision analytic model. ${ }^{9}$ Probabilities were 
Table 3: Cost-effectiveness analysis results: overall patient population ${ }^{a}$

\begin{tabular}{lccccc}
\hline Strategy & $\begin{array}{c}\text { Cost } \\
\text { (\$) }\end{array}$ & $\begin{array}{c}\text { Incremental } \\
\text { Cost (\$) }\end{array}$ & $\begin{array}{c}\text { Effectiveness } \\
\text { (QALYs) }\end{array}$ & $\begin{array}{c}\text { Incremental } \\
\text { Effectiveness } \\
\text { (QALYs) }\end{array}$ & $\begin{array}{c}\text { Incremental } \\
\text { Cost-Effectiveness } \\
\text { Ratio (\$/QALY) }\end{array}$ \\
\hline CTAP & 147,116 & - & 13.81 & - & Dominated \\
TCD & 154,718 & 7601 & 13.62 & -0.1972 & .
\end{tabular}

${ }^{a}$ CTAP imaging strategy is used as the reference in the incremental cost-effectiveness results.

\section{Cost-Effectiveness Analysis}

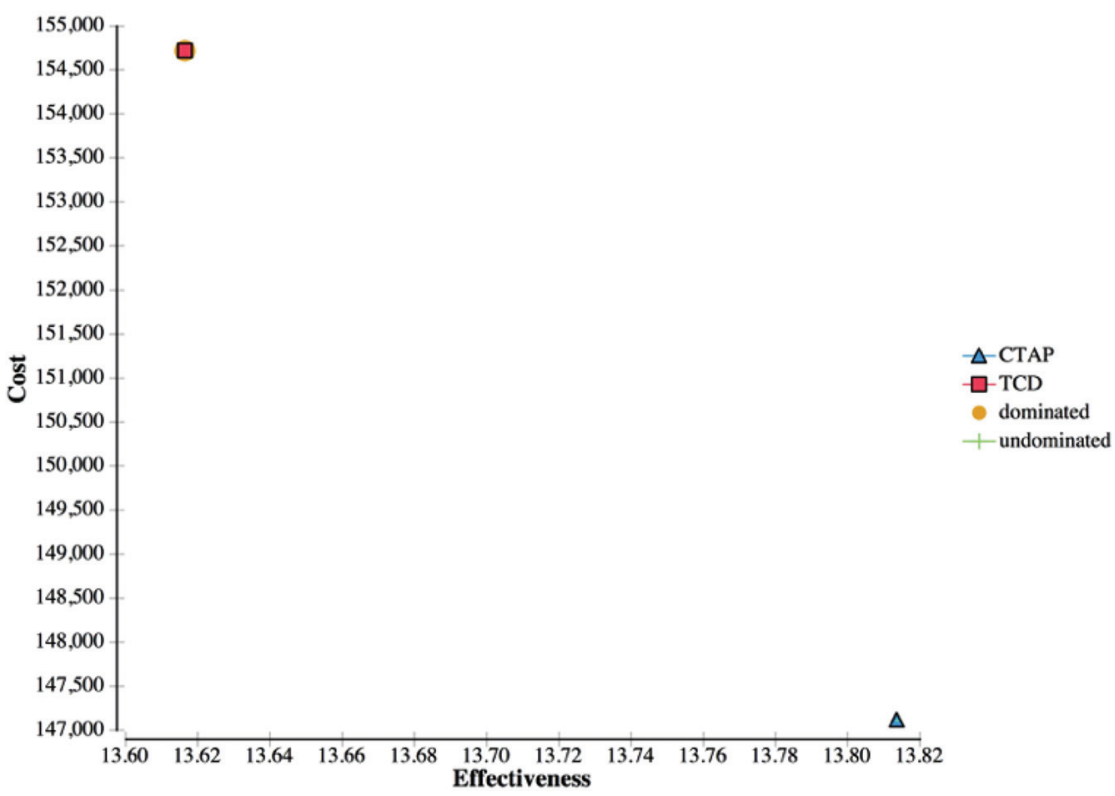

FIG 1. Cost-effectiveness analysis results. The CTAP strategy had greater QALYs and lower cost than the TCD strategy after incorporating the risks of brain cancer and cataract.

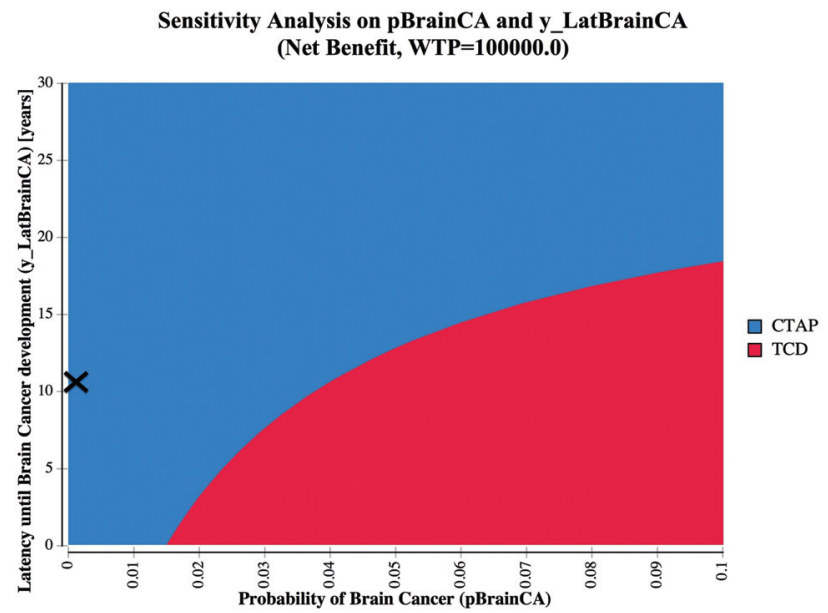

FIG 2. Two-way sensitivity analysis on the probability of brain cancer and the latency of brain cancer overall in the patient population. The CTAP strategy is indicated in blue, and the TCD strategy is indicated in red. $X$ denotes the base case (latency of brain cancer $=10.7$ years based on published literature; modeled probability of brain cancer $=$ $0.0002725 ; 95 \% \mathrm{Cl}, 0.000053-0.000802$ ). A willingness-to-pay (WTP) threshold of $\$ 100,000$ was assumed.

calculated by using a conditionally dependent multinomial prediction model.

A mean brain cancer latency of 10.7 years after exposure was used in the model based on published literature. ${ }^{12}$ The risk of cataract from radiation exposure related to CTAP was estimated at 0.0025 based on published literature. ${ }^{13}$ The average latency of cataract is reported as 6 years after exposure. ${ }^{14}$

Risks from Radiation Exposure. Lifetime brain cancer risk from CTAP was calculated by using National Cancer Institute (NCI) methodology (https://irep.nci. nih.gov/radrat/) and adjusted for life expectancy. ${ }^{15}$ As demonstrated in Table 2, the risks differed on the basis of patient sex, age, and life expectancy. We conservatively elected to use the highest modeled risk as the base case risk of radiation-induced brain cancer included in the model, which was 27.25 per 100,000 persons per year (95\% CI, 5.3-80.2 per $100,000)$ in a 50 -year-old male patient with normal life expectancy (Table 2). The average brain effective dose from NCCT/CTAP used in the risk calculation was $16.4 \mathrm{mSv}$ (range, 11.8-27.3 $\mathrm{mSv}$ ), and the mean dose-length product was $6790.0 \mathrm{mGy} \times \mathrm{cm}$, based on published literature. ${ }^{16}$ Of note, this mean effective dose has been further decreased in recent years, with published studies citing comprehensive acute stroke protocol NCCT/CTAP doses of up to $10.6 \mathrm{mSv} .{ }^{17}$ However, we sought a conservative approach and elected to use the higher mean effective dose of $16.4 \mathrm{mSv}$ because the empiric patient cohort used as a basis for our decision analytic model had received this dose. Furthermore, our model results would represent the higher limit of radiation exposure from CTAP imaging in this cohort.

\section{Outcomes}

Health Outcomes. Outcome health states reflect functional outcomes from $\mathrm{SAH}$, incorporating quality-of-life impairments associated with cataract formation and developing brain cancer.

The probabilities for long-term clinical outcomes from SAH, representing health states, were categorized as recovered (mRS, $0-2)$, disability (mRS, 3-5), or death (mRS, 6) and were derived from the International Subarachnoid Aneurysm Trial. ${ }^{1}$

Utility Weights and Quality-Adjusted Life Years. Utilities were calculated as a weighted average from a systematic review of utilities assigned according to $\mathrm{mRS}$ scores. The utilities of recovered and disability were 0.80 and 0.22 , respectively. ${ }^{18}$ Life expectancies in each health state were derived from literature review as 28 years for recovered (mRS, 0-2), ${ }^{19}$ and 10.8 years for disability (mRS, $3-5) .{ }^{20}$ Death was assigned a value of zero for both life years and utility.

The utility of brain cancer of 0.692 was assumed on the basis of published literature. ${ }^{21}$ The utility of cataract of 0.86 was assumed on the basis of published literature. ${ }^{22}$ 
Table 4: One-way sensitivity analysis results: probability of cataract ${ }^{a}$

\begin{tabular}{|c|c|c|c|c|c|c|}
\hline $\begin{array}{c}\text { Probability of } \\
\text { Cataract }\end{array}$ & Strategy & Cost (\$) & $\begin{array}{l}\text { Effectiveness } \\
\text { (QALYs) }\end{array}$ & $\begin{array}{l}\text { Incremental } \\
\text { Cost (\$) }\end{array}$ & $\begin{array}{l}\text { Incremental } \\
\text { Effectiveness } \\
\text { (QALYs) }\end{array}$ & $\begin{array}{c}\text { Incremental } \\
\text { Cost-Effectiveness } \\
\text { Ratio (\$/QALY) }\end{array}$ \\
\hline 0 & CTAP & 147,110 & 13.81 & 0 & 0 & \\
\hline 0 & $\mathrm{TCD}$ & 154,719 & 13.62 & 7608.40 & -0.20 & Dominated \\
\hline 0.2 & CTAP & 147,625 & 13.80 & 0 & 0 & \\
\hline 0.2 & $\mathrm{TCD}$ & 154,719 & 13.62 & 7094.12 & -0.18 & Dominated \\
\hline 0.4 & CTAP & 148,139 & 13.78 & 0 & 0 & \\
\hline 0.4 & TCD & 154,719 & 13.62 & 6579.84 & -0.17 & Dominated \\
\hline 0.6 & CTAP & 148,653 & 13.77 & 0 & 0 & \\
\hline 0.6 & TCD & 154,719 & 13.62 & 6065.56 & -0.15 & Dominated \\
\hline 0.8 & CTAP & 149,168 & 13.75 & 0 & 0 & \\
\hline 0.8 & $\mathrm{TCD}$ & 154,719 & 13.62 & 5551.28 & -0.13 & Dominated \\
\hline 1 & CTAP & 149,682 & 13.73 & 0 & 0 & \\
\hline 1 & $\mathrm{TCD}$ & 154,719 & 13.62 & 5037.00 & -0.12 & Dominated \\
\hline
\end{tabular}

${ }^{a}$ In a 1-way sensitivity analysis, CTAP remained the optimal strategy when varying the probability of cataract from 0.0 to 1.0 .

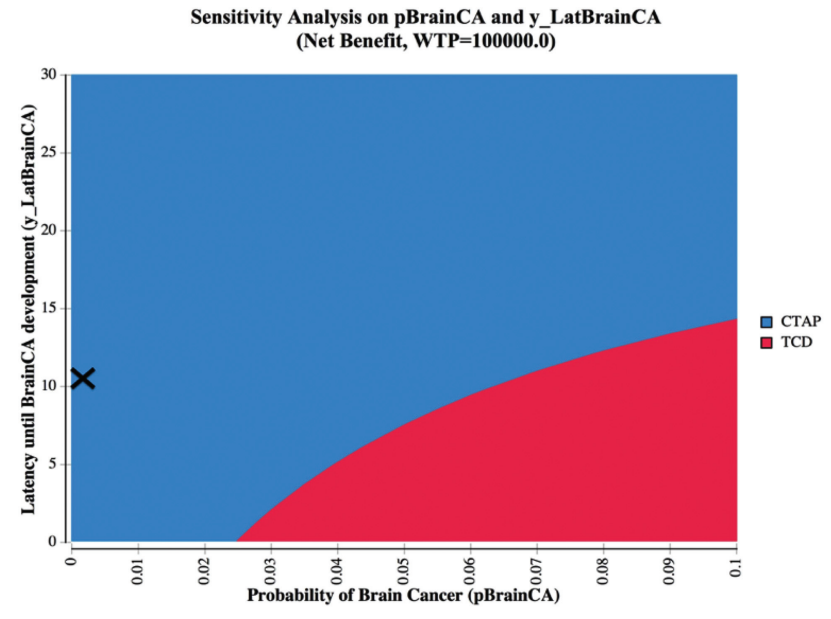

FIG 3. Two-way sensitivity analysis on the probability of brain cancer and the latency of brain cancer and subanalysis of the asymptomatic patient population. The CTAP strategy is indicated in blue, and the TCD strategy is indicated in red. $X$ denotes the base case (latency of brain cancer $=10.7$ years based on published literature; modeled probability of brain cancer $=0.0002725 ; 95 \% \mathrm{Cl}, 0.000053-0.000802$ ). A willingness-to-pay (WTP) threshold of $\$ 100,000$ was assumed.

Health outcomes were expressed as quality-adjusted-life years gained for each imaging strategy. Lifetime QALYs were calculated by multiplying the sum of the number of years spent in each health state by the utility associated with that state.

Cost Outcomes. Evaluation of costs included only direct medical costs; indirect costs such as loss of earnings through inability to work were omitted according to standard methods in performing cost-effectiveness analyses in the United States. Imaging costs were based on the 2012 Medicare rates (including both technical and professional fees) based on the Current Procedural Terminology codes. The 2012 rates were chosen to maintain consistency with our empiric cohort. The total costs for long-term care in each health state were estimated from the literature and multiplied by the life expectancy. Current values for both benefits and costs were calculated by discounting the original values at a rate of $3 \%$ per year, as recommended for cost-effectiveness analyses in the United States. ${ }^{23}$ Costs of brain cancer $^{24}$ and cataract surgery ${ }^{25}$ were estimated on the basis of published literature.

\section{Statistical Analyses}

Incremental cost-effectiveness ratios were calculated as well as the incremental cost per QALY gained. Univariable and multivariable sensitivity analyses were performed to determine the independent and combined effect of input parameter uncertainty. A willingness-to-pay threshold of $\$ 100,000 / \mathrm{QALY}$ was assumed on the basis of previously published work. ${ }^{9}$ Two-way sensitivity analyses were performed to evaluate the impact of the following: 1) the probability of brain cancer and latency until brain cancer development, and 2) the probability of cataract and latency until cataract development based on model results. A scenario analysis considering only asymptomatic patients was also performed.

To assess overall model uncertainty, we conducted probabilistic sensitivity analysis in which 10,000 simulations were performed. The selected key variables were assumed to have triangular distributions. In a separate probabilistic sensitivity analysis, the range of the probability of brain cancer was extended to incorporate an upper limit of 5\% (>50 times the upper limit of the $95 \%$ confidence interval), and 10,000 simulations of the model were repeated.

\section{RESULTS}

The per-person cost for the CTAP strategy was $\$ 147,116$. The per-person cost for the TCD strategy was $\$ 154,718$. The CTAP strategy resulted in a gain of 13.81 QALYs. The TCD strategy resulted in a gain of 13.62 QALYs (Table 3). Because the CTAP strategy resulted in lower cost and greater gains in QALYs, the CTAP strategy was dominant over the TCD strategy. When we varied the probability of brain cancer, the CTAP strategy remained cost-effective at $\$ 100,000 /$ QALY as long as the risk of brain cancer remained lower than approximately 4\%, compared with $0.03 \%$ in the base case. This threshold value was 50 times greater than the upper limit of the $95 \%$ confidence interval $(0.08 \%)$ (Figs 1 and 2$)$. Our results remained robust when varying the latency of brain cancer onset from 0.1 years to 30 years at base case brain cancer risk (Fig 2).

In 2-way sensitivity analysis, the CTAP strategy remained dominant over the TCD strategy under all circumstances when the probability of cataract was varied from 0 to 1 and cataract 
Table 5: Cost-effectiveness analysis results: asymptomatic patient population subanalysis ${ }^{\mathrm{a}}$

\begin{tabular}{lccccc}
\hline Strategy & Cost (\$) & $\begin{array}{c}\text { Incremental } \\
\text { Cost (\$) }\end{array}$ & $\begin{array}{c}\text { Incremental } \\
\text { Effectiveness } \\
\text { (QALYs) }\end{array}$ & $\begin{array}{c}\text { Incremental } \\
\text { Effectiveness } \\
\text { (QALYs) }\end{array}$ & $\begin{array}{c}\text { Cost-Effectiveness } \\
\text { Ratio (\$/QALY) }\end{array}$ \\
\hline CTAP & 145,247 & - & 13.86 & - & Dominated \\
TCD & 156,272 & 11,024 & 13.51 & -0.3517 & Dit
\end{tabular}

${ }^{a}$ CTAP imaging strategy is used as the reference in the incremental cost-effectiveness results.

CE Acceptability Curve

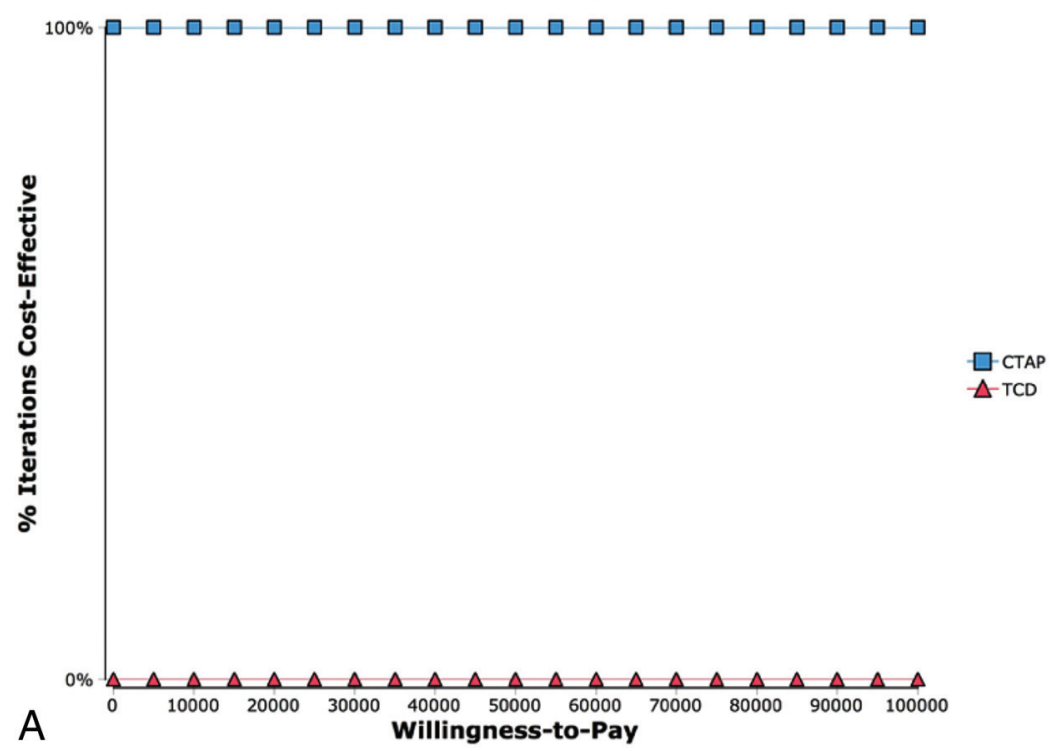

CE Acceptability Curve

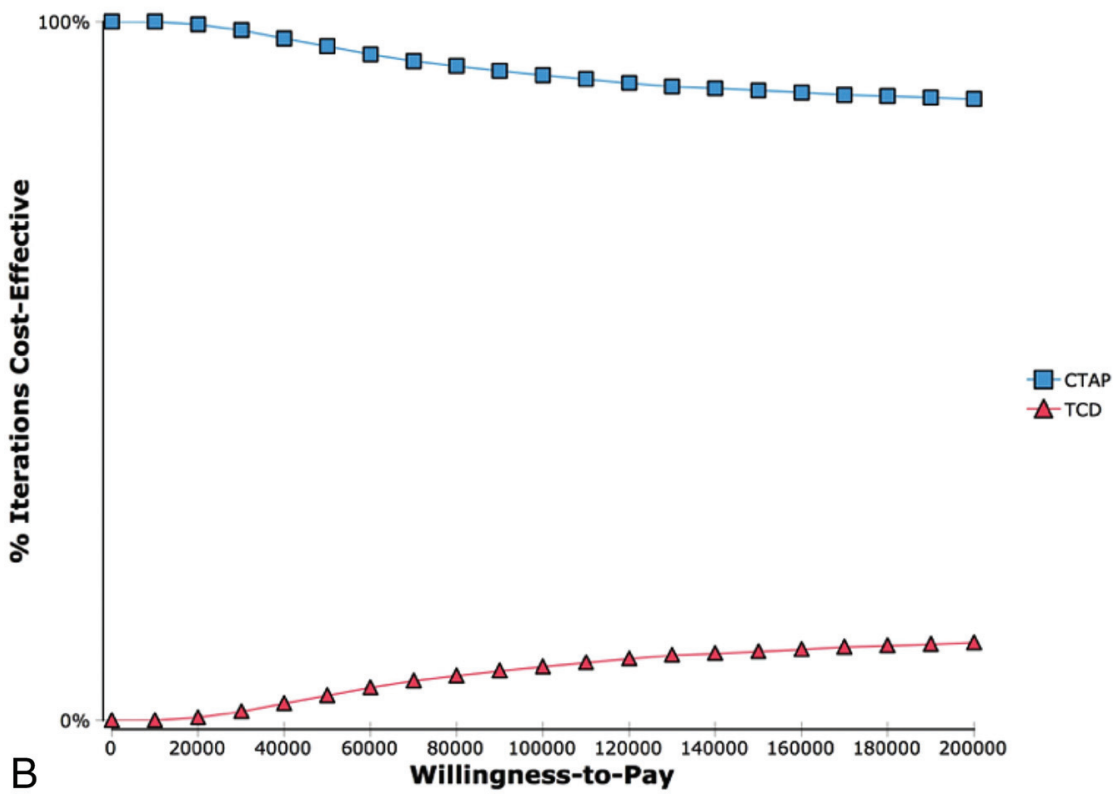

FIG 4. Cost-effectiveness (CE) acceptability curves. CE acceptability curves were calculated incorporating distributions reported in the literature and the probability of brain cancer as modeled on the basis of $\mathrm{NCl}$ methodology ( $A$, see Table 1) and, in a separate subanalysis, incorporating an upper limit of the probability of brain cancer of $5 \%$ (ie, $>50$ times higher than the calculated $95 \%$ confidence interval upper limit of 80.16 per $100,000, B$ ).

latency was varied from 0.1 to 30 years. Table 4 demonstrates results of a 1-way sensitivity analysis varying the probability of cataract from 0 to 1 when there was no condition for which TCD was preferred.
A scenario analysis of asymptomatic patients with SAH did not change the results; CTAP remained the dominant strategy compared with TCD (Fig 3 and Table 5).

In probabilistic sensitivity analysis, CTAP was the preferred strategy in $100 \%$ of iterations across a broad range of willingness-to-pay threshold values (Fig 4A). When the upper limit of the probability distribution for developing brain cancer was increased to $5 \%$ (compared with the upper limit of the $95 \%$ confidence interval, $0.08 \%$; Table 2), CTAP was still preferred in $>92 \%$ of iterations at a willingness-to-pay value below $\$ 100,000 /$ QALY (Fig 4B).

\section{DISCUSSION}

Our model demonstrates that while the development of brain cancer and cataract from radiation exposure in patients undergoing CTAP is an important consideration, it does not alter CTAP as the preferred imaging strategy in SAH compared with TCD. Similar to our prior analysis that did not incorporate these radiation-induced complications, we found that CTAP leads to greater qualityadjusted life expectancy for patients with SAH and lower health care costs after incorporating brain cancer and cataract risk. These findings were robust across a broad range of plausible values and remained consistent even after modeling a significantly higher risk and shorter latency period than known from current literature. Moreover, we conservatively elected to use the highest modeled risk (50-year-old male patient with normal life expectancy) for our base case scenario. This age approximates the median age of a patient with SAH in published cohorts. ${ }^{1}$ If we had assumed a higher age or additional comorbidities, results would have been even more favorable for CTAP because of lower lifetime brain cancer risk (Table 2).

In recent years, CTAP has become increasingly recognized as an important prognostic tool in patients with $\mathrm{SAH}$, especially given the recognized importance of cerebral blood flow evaluation in the prediction of poor clinical outcomes. ${ }^{26}$ Moreover, recent studies have shown that blood-brain barrier permeability evaluation with CTAP may become an important early prognostic marker of global cerebral edema ${ }^{27}$ and delayed cerebral isch- 
emia. ${ }^{28}$ Early identification of these complications before they become apparent on noncontrast CT further increases the utility of CTAP. Furthermore, CTAP radiation doses have gradually decreased in recent years in an effort to decrease radiation exposure to the patient, with published studies citing comprehensive acute stroke protocol NCCT/CTAP doses of up to $10.6 \mathrm{mSv} .{ }^{17}$ Therefore, the radiation risk assumed in our model may, in fact, be overestimated, further supporting CTAP as the superior imaging technique in patients with SAH.

While radiation risk is an important consideration when selecting the appropriate imaging technique, our study shows that after we account for the risk of developing radiation-induced brain cancer and the risk of developing radiation-induced cataract, CTAP remains the superior imaging technique in patients with SAH, resulting in improved clinical outcomes and lower health care costs. This has important implications in the clinical decision-making for the management of patients with SAH, supporting the use of CTAP imaging.

The main limitation of our study is that a decision-modeling study design was performed instead of a prospective randomized clinical trial. Decision analytic models can help inform clinical decision-making by considering all potential consequences, incorporating the best available evidence, and considering uncertainty in estimates. Such models are particularly useful when randomized controlled trials are not feasible, such as in the case of gauging the contribution of radiation exposure effects on management strategies for SAH. This scenario is particularly relevant in this study given the long-term latency period associated with radiation-induced brain cancer. Another limitation in decision modeling is the variability of the input parameters. However, we performed several types of sensitivity analyses (1-way, 2-way, and probabilistic) to assess the variability of each input in the model results.

\section{CONCLUSIONS}

While there have been, to our knowledge, no randomized trials directly comparing the impact of different imaging modalities on clinical outcomes of patients with $\mathrm{SAH}$, recent publications have demonstrated the added benefit of CTAP imaging in the detection of vasospasm and perfusion deficits. ${ }^{9,29}$ Moreover, CT perfusion imaging has the added benefit of evaluating delayed cerebral ischemia, an important SAH complication and determinant of poor clinical outcomes in $\mathrm{SAH},{ }^{26}$ which is particularly important given the limitations of clinical examination ${ }^{30}$ and $\mathrm{TCD}^{31}$ in this patient population.

Until recently, the focus has been on avoiding any kind of radiation exposure related to CT-based imaging, focusing on sonography-based methods instead. However, our study shows that the significant health benefits of CTAP outweigh the risks related to radiation exposure, even when modeling a far greater brain cancer risk than has been determined by using NCI methodology.

Future studies assessing the clinical and cost effectiveness of other imaging studies associated with radiation exposure should include the short- and long-term effects of radiation exposure to provide a comprehensive analysis of the benefits and risks for a given patient population.

Disclosures: Jana Ivanidze—RELATED: Grant: Radiological Society of North America Research and Education Foundation Resident Research Grant, Comments: Resident Research Grant (awarded to J.I.) 2014-2015.

\section{REFERENCES}

1. Molyneux AJ, Kerr RS, Birks J, et al; ISAT Collaborators. Risk of recurrent subarachnoid haemorrhage, death, or dependence and standardised mortality ratios after clipping or coiling of an intracranial aneurysm in the International Subarachnoid Aneurysm Trial (ISAT): long-term follow-up. Lancet Neurol 2009;8:427-33 CrossRef Medline

2. Springer MV, Schmidt JM, Wartenberg KE, et al. Predictors of global cognitive impairment 1 year after subarachnoid hemorrhage. $\mathrm{Neu}$ rosurgery 2009;65:1043-50; discussion 1050-51 CrossRef Medline

3. Chou CH, Reed SD, Allsbrook JS, et al. Costs of vasospasm in patients with aneurysmal subarachnoid hemorrhage. Neurosurgery 2010;67:345-51; discussion 351-52 CrossRef Medline

4. Rivero-Arias O, Gray A, Wolstenholme J. Burden of disease and costs of aneurysmal subarachnoid haemorrhage (aSAH) in the United Kingdom. Cost Eff Resour Alloc 2010;8:6 CrossRef Medline

5. Smith-Bindman R, Lipson J, Marcus R, et al. Radiation dose associated with common computed tomography examinations and the associated lifetime attributable risk of cancer. Arch Intern Med 2009; 169:2078-86 CrossRef Medline

6. Amis ES Jr, Butler PF; American College of Radiology. ACR white paper on radiation dose in medicine: three years later. J Am Coll Radiol 2010;7:865-70 CrossRef Medline

7. Wintermark M, Lev MH. FDA investigates the safety of brain perfusion CT. AJNR Am J Neuroradiol 2010;31:2-3 CrossRef Medline

8. Goehler A, Gazelle GS. Examining the use of comparative and costeffectiveness analyses in radiology. AJR Am J Roentgenol 2014;203: 939-44 CrossRef Medline

9. Sanelli PC, Pandya A, Segal AZ, et al. Cost-effectiveness of CT angiography and perfusion imaging for delayed cerebral ischemia and vasospasm in aneurysmal subarachnoid hemorrhage. AJNR Am J Neuroradiol 2014;35:1714-20 CrossRef Medline

10. Meyers PM, Schumacher HC, Higashida RT, et al; Joint Writing Group of the Technology Assessment Committee, Society of Neurolnterventional Surgery, Society of Interventional Radiology, Joint Section on Cerebrovascular Neurosurgery of the American Association of Neurological Surgeons and Congress of Neurological Surgeons, Section of Stroke and Interventional Neurology of the American Academy of Neurology. Reporting standards for endovascular repair of saccular intracranial cerebral aneurysms. J Neurointerv Surg 2010;2:312-23 CrossRef Medline

11. Miller JA, Dacey RG Jr, Diringer MN. Safety of hypertensive hypervolemic therapy with phenylephrine in the treatment of delayed ischemic deficits after subarachnoid hemorrhage. Stroke 1995;26: 2260-66 CrossRef Medline

12. Kranzinger M, Jones $\mathrm{N}$, Rittinger $\mathrm{O}$, et al. Malignant glioma as a secondary malignant neoplasm after radiation therapy for craniopharyngioma: report of a case and review of reported cases. Onkologie 2001;24:66-72 Medline

13. Yuan MK, Tsai DC, Chang SC, et al. The risk of cataract associated with repeated head and neck CT studies: a nationwide populationbased study. AJR Am J Roentgenol 2013;201:626-30 CrossRef Medline

14. Henk JM, Whitelocke RA, Warrington AP, et al. Radiation dose to the lens and cataract formation. Int J Radiat Oncol Boil Phys 1993;25: 815-20 CrossRef Medline

15. Berrington de Gonzalez A, Iulian Apostoaei A, Veiga LH, et al. RadRAT: a radiation risk assessment tool for lifetime cancer risk projection. J Radiol Prot 2012;32:205-22 CrossRef Medline

16. Mnyusiwalla A, Aviv RI, Symons SP. Radiation dose from multidetector row CT imaging for acute stroke. Neuroradiology 2009;51: 635-40 CrossRef Medline

17. Diekmann S, Siebert E, Juran R, et al. Dose exposure of patients undergoing comprehensive stroke imaging by multidetector-row CT: comparison of 320-detector row and 64-detector row CT scanners. AJNR Am J Neuroradiol 2010;31:1003-09 CrossRef Medline

18. Post PN, Stiggelbout AM, Wakker PP. The utility of health states after stroke: a systematic review of the literature. Stroke 2001;32: 1425-29 CrossRef Medline

19. de Rooij NK, Linn FH, van der Plas JA, et al. Incidence of subarach- 
noid haemorrhage: a systematic review with emphasis on region, age, gender and time trends. J Neurol Neurosurg Psychiatry 2007;78: 1365-72 CrossRef Medline

20. Kallmes DF, Kallmes MH. Cost-effectiveness of angiography performed during surgery for ruptured intracranial aneurysms. AJNR Am J Neuroradiol 1997;18:1453-62 Medline

21. McCarter H, Furlong W, Whitton AC, et al. Health status measurements at diagnosis as predictors of survival among adults with brain tumors. J Clin Oncol 2006;24:3636-43 CrossRef Medline

22. Busbee BG, Brown MM, Brown GC, et al. Cost-utility analysis of cataract surgery in the second eye. Ophthalmology 2003;110: 2310-17 CrossRef Medline

23. Weinstein MC, Siegel JE, Gold MR, et al. Recommendations of the Panel on Cost-Effectiveness in Health and Medicine. JAMA 1996; 276:1253-58 CrossRef Medline

24. Martino J, Gomez E, Bilbao JL, et al. Cost-utility of maximal safe resection of WHO grade II gliomas within eloquent areas. Acta Neurochir (Wien) 2013;155:41-50 CrossRef Medline

25. Camejo MD, Rupani MK, Rebenitsch RL. A comparative analysis of the cost of cataract surgery abroad and in the United States. Indian J Ophthalmol 2014;62:748-49 CrossRef Medline

26. Sanelli PC, Anumula N, Johnson CE, et al. Evaluating CT perfusion using outcome measures of delayed cerebral ischemia in aneurysmal subarachnoid hemorrhage. AJNR Am J Neuroradiol 2013;34: 292-98 CrossRef Medline

27. Ivanidze J, Kallas ON, Gupta A, et al. Application of blood-brain barrier permeability imaging in global cerebral edema. AJNR Am J Neuroradiol 2016;37:1599-603 CrossRef Medline

28. Ivanidze J, Kesavabhotla K, Kallas ON, et al. Evaluating blood-brain barrier permeability in delayed cerebral infarction after aneurysmal subarachnoid hemorrhage. AJNR Am J Neuroradiol 2015;36: 850-54 CrossRef Medline

29. Dankbaar JW, de Rooij NK, Velthuis BK, et al. Diagnosing delayed cerebral ischemia with different $\mathrm{CT}$ modalities in patients with subarachnoid hemorrhage with clinical deterioration. Stroke 2009;40: 3493-98 CrossRef Medline

30. Schmidt JM, Wartenberg KE, Fernandez A, et al. Frequency and clinical impact of asymptomatic cerebral infarction due to vasospasm after subarachnoid hemorrhage. J Neurosurg 2008;109:1052-59 CrossRef Medline

31. Carrera E, Schmidt JM, Oddo M, et al. Transcranial Doppler for predicting delayed cerebral ischemia after subarachnoid hemorrhage. Neurosurgery 2009;65:316-23; discussion 323-24 CrossRef Medline 